\title{
EMPLOYMENT AS A DRUG ABUSE TREATMENT INTERVENTION: \\ A BEHAVIORAL ECONOMIC ANALYSIS
}

\author{
Kenneth Silverman \\ Elias Robles
}

Working Paper 6402 
NBER WORKING PAPER SERIES

\title{
EMPLOYMENT AS A DRUG ABUSE TREATMENT INTERVENTION: A BEHAVIORAL ECONOMIC ANALYSIS
}

\author{
Kenneth Silverman \\ Elias Robles
}

\author{
Working Paper 6402 \\ http://www.nber.org/papers/w6402
}

\section{NATIONAL BUREAU OF ECONOMIC RESEARCH \\ 1050 Massachusetts Avenue \\ Cambridge, MA 02138 \\ February 1998}

This paper was prepared for an NBER conference on The Economic Analysis of Substance Use and Abuse: An Integration of Econometric and Behavioral Economic Research (held March 27-28, 1997, Cambridge, MA). Supported by grants R01 DA09426 and P50 DA09258 from the National Institute on Drug Abuse. Any opinions expressed are those of the authors and not those of the National Bureau of Economic Research.

(C) 1998 by Kenneth Silverman and Elias Robles. All rights reserved. Short sections of text, not to exceed two paragraphs, may be quoted without explicit permission provided that full credit, including (C) notice, is given to the source. 
Employment as a Drug Abuse Treatment Intervention:

A Behavioral Economic Analysis

Kenneth Silverman and Elias Robles

NBER Working Paper No. 6402

February 1998

\begin{abstract}
Epidemiological data and experimental research in the fields of operant conditioning and behavioral economics suggest that employment may be useful in the treatment of drug abuse. The conditions under which employment should decrease drug use depends on a range of environmental contextual factors, some of which have been classified or suggested by adapting the economic concepts of income, substitutability and complementarity, and opportunity cost to the analysis of behavior. A job can occupy a substantial portion of a person's day with work, thereby reducing the amount of time available for drug consumption (i.e., employment reduces behavioral income for drug use). Because money buys drugs, monetary pay for work may increase or sustain drug use, suggesting a potential undesirable by-product of employment (i.e., money and drugs appear to be complementary reinforcers). Finally, employment may decrease drug use to the extent that drug use results in loss of wages or job termination (i.e., employment may impose an opportunity cost of drug use). This paper reviews research in these three areas with the goal of identifying an effective employment-based treatment intervention for chronically unemployed methadone patients, a group of individuals sorely in need of effective interventions to reduce their drug use and improve their employment status. Research on behavioral income restrictions, reinforcer substitutability and complementarity, and opportunity cost suggests that the utility of employment as a drug abuse treatment intervention depends, in large part, on the extent to which employment is used to arrange substantial monetary reinforcement for drug abstinence and opportunity cost for drug use. In this capacity, employment could serve a valuable role in the treatment of hard-core drug abuse as a vehicle for funding, implementing, and sustaining reinforcement contingencies for drug abstinence and opportunity cost for drug use, procedures which have been shown in controlled clinical trials to be among the more effective drug abuse treatments currently in use.
\end{abstract}

Kenneth Silverman

Department of Psychiatry and Behavioral Sciences

Johns Hopkins University

School of Medicine

5510 Nathan Shock Drive

Baltimore, MD 21224
Elias Robles

Department of Psychiatry and Behavioral Sciences

Johns Hopkins University

School of Medicine

5510 Nathan Shock Drive

Baltimore, MD 21224 


\section{INTRODUCTION}

\section{Associations Between Drug Use and Unemployment}

Descriptive and experimental data suggest that employment may be useful in the treatment of drug abuse. Descriptive data from a variety of sources show that unemployment and drug use are closely associated. Review of data from the 1991 National Household Surveys on Drug Use (SAMHSA, 1993; Gfroerer et al., 1993) reveals striking and statistically significant relationships in the general population between unemployment and an increased prevalence of use of heroin, cocaine, crack, marijuana, hallucinogen, PCP, heavy alcohol use, and nonmedical use of sedatives, tranquilizers, and analgesics. Similar relationships between unemployment and drug use have been observed in previous surveys (NIDA, 1988, 1990, 1991). This relationship between drug use and unemployment is illustrated in Figure 1 which shows rates of illicit drug use by employment status based on the National Household Surveys on Drug Abuse from 1988 to 1993 (SAMHSA, 1996). This figure shows that both employed and unemployed adults in the U.S. report using illicit drugs, but across all years of this survey unemployed adults reported the highest rates of illicit drug use and full-time workers reported the lowest rates. Across these years, rates of illicit drug use among unemployed adults ranged form 1.7 to 2.5 times higher than the rates of illicit drug use among adults employed full-time.

\section{Insert Figure 1 About Here}

Unemployment and drug use appears to be associated within the population of drug abusers participating in treatment, as well. This is evidenced, in part, by the fact that a substantial proportion of patients in drug abuse treatment programs are unemployed. The large-scale Treatment Outcome Prospective Study (TOPS; Hubbard et al., 1989) of 11,000 drug abusers who were treated in 41 different drug abuse treatment programs in the U.S shows the high rates of unemployment among drug abuse treatment patients. In this studye, patients from three different treatment modalities (outpatient methadone, residential, and outpatient drug-free treatment) were 
asked about their employment status from the period starting 1 year before treatment to 5 years after treatment. Fewer than $50 \%$ of individuals from any of the treatment modalities reported fulltime employment, and fewer $30 \%$ of the methadone patients reported full-time employment in any of the years assessed.

Furthermore, among persons in drug abuse treatment, unemployment has been associated with poor treatment outcome. Unemployment has been correlated with poor treatment retention, higher rates of drug use during treatment, and increased relapse rates (Frykholm, Gunne, Huitsfeldt, 1976; Mclellan, Ball, Rosen, \& O'Brien, 1981; McLellan, Luborsky, Woody, O'Brien, \& Druley, 1983; Platt, 1995; Stephens \& Cottrell, 1982; Vaillant, 1966a; Vaillant , 1966b; Vaillant, 1988). Some of the most impressive data are provided in a classic study by Vaillant who followed 100 hospitaltreatment heroin addicts for 20 years after hospital discharge. In one analysis, Vaillant (1988) compared 30 heroin addicts who remained most chronically addicted to heroin during the 12 years following discharge to 30 addicts who achieved 3 or more years of sustained abstinence during the follow-up period. Sustained abstinence was significantly associated with long employment histories: Sixty-three percent of addicts who achieved sustained abstinence had been employed for half or more of their adult life, whereas none of the chronically addicted persons had such employment histories. While these associations do not demonstrate that unemployment is a cause of drug abuse or that increasing employment could decrease drug use, the unequivocal relationship between unemployment and drug use strongly suggests the need to investigate further the potential role of employment in drug abuse, and particularly in drug abuse treatment.

\section{Work As An Alternative Operant Behavior to Drug Use}

The suspicion that employment may be useful in the treatment of drug abuse is further raised by two very general and interrelated findings in the field of operant conditioning. The first finding is that drug use is operant behavior, maintained and modifiable by it consequences. This has been shown in a large number of controlled, laboratory studies which have demonstrated that drugs can serve as reinforcers that maintain drug seeking and drug self-administration in humans and in non-humans (Griffiths et al., 1980; Johanson \& Schuster, 1981; Pickens et al., 1978). The 
second finding is that drug self-administration can be decreased by reinforcing an alternative and incompatible behavior with non-drug reinforcers. Laboratory studies in animals and in humans have shown that self-administration of a range of drugs can be decreased by reinforcing alternative incompatible responses with a range of non-drug reinforcers (Carroll, 1995; Bickel \& DeGrandpre, 1995). Reinforcing work with money as an alternative to drug use surely fits within this model (c.f., Bickel \& DeGrandpre, 1995; Bickel, DeGrandpre, Higgins, Hughes, \& Badger, 1995).

The effects on drug self-administration of reinforcing work with money is illustrated in a recent experiment by Bickel et al. (1995). In this study, cigarette smokers reported to the laboratory for 3 hours sessions during which they could earn two puffs on a cigarette each time they completed a specified number lever pulls on a computer-controlled response console. The price of cigarette puffs was varied across days by varying the number of lever pulls required to earn cigarette puffs. On some days, subjects could also earn money for emitting a different response (400 pulls on a different lever). Two results of this study are important to note. First, cigarette smoking was decreased in all subjects when subjects could earn money for emitting an alternative response. Second, although reinforcing an alternative response with money decreased cigarette smoking, smoking persisted to some extent even when the alternative response was reinforced.

\section{Studies of Supportive Employment in Drug Abusers}

Although the descriptive and experimental studies described above provide good reason to expect that employment may reduce drug use, a few controlled evaluations of supported employment interventions in drug abusers have failed to show consistent effects on drug use. Supported employment programs provide persons with severe employment problems subsidized employment under conditions that are designed to shape effective work and work-related skills. Three studies have been done in which dng abusers were randomly assigned to receive a supported employment intervention or a no-treatment control condition (Bass \& Woodward, 1978; Friedman, 1980; Dickinson et al., 1981). Their results can be illustrated by one study conducted 
by Dickinson et al. (1981). In that study, 1,154 drug abusers were randomly assigned to a supported work or control group. Supported work subjects participated in the supported work program for 12 to 18 months; the controls had to find their own work. Supported work subjects were given labor-intensive jobs at wage rates slightly below fair-market value. During the first 3 months, $86 \%$ of supported work subjects participated. Experimental subjects worked significantly more hours than controls; however the number of hours worked dropped sharply across the first 15 months of the study. Supported work significantly reduced criminal activity as indicated by decreased arrest rates, convictions, and time incarcerated. Supported work did not affect selfreports of drug use, but did significantly decrease self-reports of daily alcohol use. After termination of supported employment, the differences between supported work subjects and controls were diminished, possibly due to the lack job opportunities. The studies on supported employment had methodological limitations (Hall, 1990), so it is difficult to draw firm conclusions from them, but supported employment appeared to have, at best, inconsistent effects on drug use: Supported employment did not reduce drug use in two of the studies (Dickinson et al., 1981; Friedman, 1980), and may have had beneficial effects in one (Bass \& Woodward, 1978).

\section{Employment Features that May Affect Drug Use}

While these descriptive and experimental data suggest that employment may have some therapeutic value in reducing drug use, the data also show that employment does not eliminate drug use. The focus of this chapter is to identify the features of employment that should determine, at least in part, employment's effect on drug use. Three features of employment and their expected effects on drug use will be considered. First, employment may have an unintended and undesirable effect of increasing or sustaining drug use by providing monetary pay which can be used to purchase drugs. Second, employment may reduce drug use by occupying time and thereby restricting the amount of time available for drug use. Third, employment may decrease drug use to the extent that drug use results in loss of wages. The ultimate aim of this analysis is to guide the development of an employment-based drug abuse treatment intervention to utilize and maximize the potential therapeutic effects of employment. 


\section{A Population of Interest: Methadone Patients}

This chapter will focus on research involving chronically unemployed methadone patients. Both unemployment (Hubbard et al., 1989) and continued illicit drug use (GAO, 1990) are serious and widespread problems in methadone patients. Cocaine abuse in methadone patients has increased to alarming rates in recent years (Condelli, Fairbank, Dennis, \& Rachal, 1991; Dunteman, Condelli, \& Fairbank, 1992; Rawson, McCann, Hasson, \& Ling, 1994), and relatively few treatments have been shown to be effective in addressing this problem (Silverman, Bigelow and Stitzer, in press). Heroin use often persists in a large proportion of patients (GAO, 1990), even when adequate doses of methadone and state-of-the-art psychosocial treatments are employed (e.g., McLellan, Arndt, Metzger, Woody, \& O'Brien, 1993).

\section{PAY FOR WORK MAY BE USED TO PURCHASE DRUGS}

Under some conditions, offering an unemployed drug abuser money for work may maintain workplace attendance and work. But whether this reinforcement contingency increases, decreases, or has no effect on drug use depends in part on the interactions between the two reinforcers, money and drugs, that maintain the behaviors of work and drug use, respectively. "Behavioral economics specifies a range of interactions that may occur among reinforcers available to a subject (Hursh, 1993; p. 169)." Two reinforcers can be substitutes, complements, or independent. "If consumption of one reinforcer (commodity B) increases with increases in price of another (commodity A), then commodity B is said to be a substitute for commodity A .... If consumption of a reinforcer decreases with increases in the price of another, then the first is said to complement the other (Hursh, 1993; p. 169)."

Importantly, these reinforcer interactions have been observed under carefully controlled laboratory conditions (Green \& Freed, 1993). This point is illustrated well in a classic experiment by Hursh (1978). Two rhesus monkeys earned all of their food and water in a chamber equipped with several levers. The monkeys could earn food by pressing on two of the levers; they could earn water by pressing on a third lever. One of the main manipulations in the experiment was to 
increase the rate of food presentation for responses on one of the levers and assess the effects on the other two levers (i.e., the other food lever and the water lever). Increasing the rate of food presentation for responses on one of the food levers decreased responding on the other food lever. Food from the two sources served as perfect substitutes. However, this manipulation had the opposite effect on water consumption: As rate of food presentation for responses on the one lever increased, the rate of responding for water and the amount of water consumed also increased. Food and water served as complements.

This study illustrates two possible effects of giving a drug abuser money for performing a job. If money is a substitute for drugs, then drug use might decrease when the drug abuser is paid for work performed. Alternatively, if money and drugs are complements, then pay for work might increase drug use. The complementary nature of money and drugs was illustrated in a laboratory study in which cigarette smokers could earn money which could be used to purchases puffs on a cigarette (DeGrandpre \& Bickel, 1995). That study found that, in general, as the wage rate for lever pressing increased, cigarette smoking also increased.

Similarly, because money can be used to purchase drugs in the natural environment, employment may have an undesirable effect of increasing or maintaining drug use by providing a monetary pay that can be used to purchase drugs. Money and drugs may serve as complementary reinforcers in that increasing the availability of money may increase the consumption of drugs. Two types of data provide indirect evidence that money and drugs can serve as complementary reinforcers. The first type of evidence comes from what drug abusers say about the relationship between money and drugs. Kirby, Lamb, Iguchi, Husband, and Platt (1995) asked 265 cocaineexperienced methadone patients to identify the types of situations in which they were likely to use cocaine. The three most frequently identified situations were having drug present $(86 \%$ of patients), being offered the drug ( $85 \%$ of patients) and having money available (83\% of patients). These data suggest that receiving monetary pay for work could possibly increase the likelihood that these methadone patients would use cocaine. These data are consistent with conventional wisdom that having money in hand frequently leads to drug use in many drug abusers. 
The second type of evidence comes from descriptive studies that investigate the relationship between the increase in availability of money and drug use in clinical populations. Shaner et al. (1995) studied patterns of cocaine use of 105 cocaine dependent schizophrenic patients who were receiving disability benefits from the Social Security Administration or from the Veterans Administration. This study showed that the percent of patients who provided cocaine positive urines was highest at the beginning of each month, shortly after patients received their disability checks, suggesting that patients were using their disability benefits to purchase cocaine. This study suggests that giving these patients cash payments may increase cocaine use, and provides some evidence that money and drugs can serve as complementary reinforcers. (For other evidence suggesting that drug use might increase when drug abusers are given an opportunity to work for money see Silverman, Kirby, and Griffiths, 1994, and Silverman, Mumford and Griffiths, 1994.)

\section{WORK OCCUPIES TIME AND THEREBY RESTRICTS ACCESS TO DRUGS}

A job can occupy a substantial portion of a person's day with work, thereby reducing the amount of time available for consumption of drugs and other reinforcers. In behavioral economic terms, the duration of access to available reinforcers has been referred to as income (Carroll \& Rodefer, 1995). This is a slightly odd use of the term income, but in the world of behavior, the opportunity to respond for a reinforcer is the primary resource needed to obtain available reinforcers, so it bares a reasonable relationship to conventional and technical definitions of income. A number of laboratory studies in nonhumans have varied income by increasing or decreasing the amount of time per day available for seeking and consuming the drugs under study (e.g., Elsmore, Fletch, Conrad, \& Sodetz, 1980; Carroll \& Rodefer, 1993; Carroll \& Rodefer, 1995; see also Carroll, this volume). These studies show that drug use can be decreased by decreasing the duration of access to the drugs, and that the amount of decrease in drug use depends on a variety of interacting factors including, but not limited to, the availability of other reinforcers, the price of available reinforcers, and the magnitude of the income restrictions.

The study by Elmore et al. (1980) illustrates an effect of restricting income in two baboons responding for food and intravenous infusions of heroin. Twenty four hours per day, each 
baboon was given repeated trials in which they could choose between an infusion of heroin ( 0.1 $\mathrm{mg} / \mathrm{kg}$ heroin $\mathrm{HCl}$ ) or four food pellets ( $750 \mathrm{mg}$ Noyes pellets). The experiment assessed the effects of increasing the amount of time between choice trials. The period between trials (i.e., the intertrial interval) was increased from 2 minutes to 12 minutes. Increasing the intertrial interval decreased the amount of time per day available for consuming the available reinforcers of heroin and food. When the intertrial interval was short, 2 minutes, the baboons could consume maximum amounts of both food and heroin. In fact under this condition, on most choice trials, the baboons did not consume either heroin or food. But as the intertrial interval increased, the number of choice trials available for consuming these two reinforcers decreased, and the animals could no longer easily maintain the high rates of consumption of both reinforcers. Food consumption remained relatively stable across the increasing intertrial intervals, but heroin consumption was substantially reduced at the higher intertrial intervals. It is important to note, that even at the extreme intertrial interval of 12 minutes, heroin consumption still persisted, albeit at substantially reduced rates (between 10 and 20 infusions per day). This study illustrates two points that are supported in other studies that have evaluated changes in income on drug use (e.g., Carroll \& Rodefer, 1993; 1995): Reducing the duration of access to available drug reinforcers can decrease drug consumption, but probably will not eliminate drug use completely, except under extreme conditions.

Evidence that employment-associated restrictions in the duration of access to drugs can reduce drug use is provided by recent studies that have assessed the effects of smoking restrictions in the workplace (Stitzer, 1995; see also Ohsfledt, this volume). In recent years, large numbers of workplaces have begun restricting smoking in the workplace. The effects of these smoking bans in the workplace provide some interesting data relevant to the current issue in that smoking bans dramatically restrict the amount of time available for smoking. To assess the effects of the bans on smoking, Brigham, Gross and Stitzer (1994) studied 34 employees at a Baltimore city hospital 4 weeks before and 4 weeks after the hospital went smoke-free. Data from these subjects were compared to 33 employees of other Baltimore hospitals that did not go smoke-free. Subjects in the 
smoke-free hospital did reduce their smoking when the smoking bans was imposed, however, none of the smokers in the smoke-free hospital quit smoking when the ban was instituted and the decreases appeared limited primarily to work hours. The number of cigarettes smoked per day did not change for control subjects. In general, these results were corroborated by measures of saliva nicotine and breath $\mathrm{CO}$ levels.

Both of these types of research show that reducing the duration of access to drugs can reduce drug use under some circumstances, although these studies do not directly address the effect that this type of intervention would have on the heroin or cocaine use of methadone patients. We do know that heroin and cocaine use can occur at fairly high rates in methadone patients even when they are employed full-time. This point is clearly illustrated in Figure 2. It shows data on the heroin and cocaine use of 151 methadone patients during the first 5 weeks of methadone maintenance treatment in a research clinic in Baltimore. The left panel shows that unemployed patients reported injecting heroin or cocaine about 17 times per week. Employed patients reported injecting slightly, but not significantly, less than that, averaging about 12 injections per week. The right panel shows data from urine samples that were collected under observation 3 times per week during this 5 -week period. About $81 \%$ of the urines samples provided by unemployed patients were positive for either opiates or cocaine. Employed patients provided significantly fewer positive samples, but still $71 \%$ of their samples were drug positive. These data show that although occupying time with work may have a beneficial effect on drug use in methadone patients, simply spending 40 hours per week at a job is in no way incompatible with substantial amounts of heroin and cocaine use.

Insert Figure 2 About Here

\section{DRUG USE CAN RESULT IN LOSS OF WAGES}

There is a substantial amount of research to suggest that employment may decrease drug use to the extent that drug use results in loss of wages or job termination. The extent to which 
drug use results in loss of wages or continued employment varies considerably across occupations and employers. At one extreme, there are employers that have mandatory and random drug testing, with specific economic sanctions for drug-positive urines (e.g., Osborn and Sokolov, 1989; 14 day suspension after 1 st drug positive, termination after second). More commonly, drug use may result in loss of wages only if it results in poor performance or attendance which over time leads to disciplinary action including termination. Behavioral economists have adapted the economic term of opportunity cost to describe this situation in which drug use results in loss of an alternative reinforcer such as money.

\section{Contingency Management Procedures}

The primary and most direct data on the utility of opportunity cost in promoting drug abstinence comes from drug abuse treatment research on contingency management procedures. For almost 20 years, drug abuse treatment researchers have been investigating the effectiveness of contingency management procedures in promoting drug abstinence (Hall, Bass, Hargreaves, \& Loeb, 1979; Stitzer et al., 1992; Stitzer and Higgins, 1995). Although until recently (Higgins, 1996) this research has been done without specific reference to behavioral economics, it is an intervention based on maximizing the opportunity cost of drug use. Under contingency management procedures, drug abuse patients receive reinforcers (e.g., money or privileges) contingent on providing objective evidence of drug abstinence (e.g., drug-free urines); drug use results in loss of the available reinforcers. Contingency management procedures have been used extensively in methadone patients and have been effective in promoting abstinence from opiates (Hall et al., 1979; McCaul, Stitzer, Bigelow, and Liebson, 1984; Higgins, Stitzer, Bigelow, and Liebson, 1986; Silverman, Wong, Higgins et al., 1996), cocaine (Kidorf and Stitzer, 1993; Silverman, Higgins, et al., 1996), benzodiazepines (Stitzer Bigelow, Liebson, \& Hawthorne, 1982) and polydrug use (Iguchi, Stitzer, Bigelow, \& Liebson, 1988; Kidorf and Stitzer, 1996; McCarthy and Borders, 1985; Milby Garrett, English, Fritschi, and Clarke, 1978; Stitzer et al., 1992). 


\section{A Monetary-Based Contingency Management Intervention}

A novel and promising contingency management intervention developed by Higgins and his colleagues (Higgins et al., 1991; Higgins et al., 1994) for the treatment of cocaine dependence is particularly relevant to the current problem because it is a monetary-based intervention. Under this contingency management system, urines are collected three times per week (frequently enough to detect most or all instances of cocaine use) and patients receive a voucher each time they provide a cocaine-free urine sample. The vouchers have monetary values that can be exchanged for goods and services that are considered consistent with the goals of treatment. To reduce the chance that patients will use their earnings to purchase drugs, voucher purchases are made for patients by the program staff (an implicit recognition that money and drugs can serve as complements as discussed above). A unique and important aspect of the procedure is the schedule of escalating voucher pay for sustained cocaine abstinence used in this procedures. Initially, the voucher values are low, but increase as the number of consecutive drug-free urines that the patient provides increases. If a patient provides a cocaine-positive urine, they do not receive a voucher and the value of the next voucher the patient receives gets reset to the initial low value. This contingency of escalating voucher pay for sustained abstinence was designed specifically to reinforce periods of sustained cocaine abstinence. Higgins and his colleagues have used this voucher intervention with considerable effectiveness in treatment of cocaine dependent patients. (For a discussion of the use of this voucher system with primary cocaine dependent outpatients see Higgins, this volume)

\section{Voucher-Based Abstinence Reinforcement In Methadone Patients}

Several studies have evaluated the effectiveness of this voucher-based contingency management intervention in promoting abstinence from cocaine and from heroin in methadone maintenance patients. The first study (Silverman, Higgins et al., 1996) assessed the effectiveness of voucher-based reinforcement in producing sustained cocaine abstinence. Patients in this study were selected from 52 consecutively admitted intravenous heroin abusers in methadone maintenance treatment at the treatment-research clinic of NIDA's intramural research program. Patients with heavy cocaine use during a 5-week baseline period $(\mathrm{N}=37)$ participated. After the 5- 
week baseline, patients were randomly assigned to an abstinence reinforcement or yoked control group and then participated in a 12-week intervention period. Patients in the abstinence reinforcement group received a voucher for each cocaine-free urine sample (i.e., negative for benzoylecgonine) provided three times per week throughout the 12-week intervention period; the vouchers had monetary values that increased as the number of consecutive cocaine-free urines increased. Patients in this group could earn up to $\$ 1155$ in vouchers for providing cocaine-free urines throughout the 12-week period. Control patients received noncontingent vouchers that were yoked (matched) in pattern and amount to the vouchers received by patients in the abstinence reinforcement group. To achieve this yoking, each control patient was yoked to a reinforcement patient who had already begun the voucher condition. On every urine collection day number from 1 to 36 ( 3 per week for 12 weeks) that the reinforcement patient earned a voucher for a cocaine-free urine, the control patient received a voucher of equal value for attending the clinic. Control patients were told that they could receive vouchers according to an unpredictable schedule and in unpredictable amounts. This procedure kept the pattern and amount of voucher presentation relatively constant across the two groups; the two groups differed only in that abstinence reinforcement subjects received vouchers contingent on providing cocaine-free urines.

Figure 3 shows the longest duration of sustained cocaine abstinence that subjects achieved during the 12-week intervention evaluation. On average, abstinence reinforcement subjects achieved significantly longer durations of sustained abstinence than control subjects. Nine abstinence reinforcement subjects (47\%) achieved between 7 and 12 weeks of sustained cocaine abstinence. In contrast only 1 yoked control subject (6\%) achieved more than 2 weeks.

Insert Figure 3 About Here

This study showed that voucher-based reinforcement of cocaine abstinence can produce sustained cocaine abstinence in a substantial proportion of hard-core cocaine abusing methadone patients. In addition, the study showed that the contingency between cocaine use and voucher 
presentation was critical in achieving the abstinence outcome. Both groups of subjects in this study received vouchers in approximately equal amounts; however, only the group that received vouchers contingent on cocaine-free urines achieved sustained cocaine abstinence. This study clearly illustrated the powerful effects of an opportunity cost intervention on cocaine use in methadone patients.

The effectiveness of this voucher-based contingency management intervention in methadone patients has now been replicated in a number of treatment-research clinics, showing that voucherbased contingency management intervention can be used to promote abstinence from cocaine (Silverman, Wong, Umbricht-Schneiter et al., 1996), opiates (Silverman, Wong, Higgins et al., 1996), and polydrug use (Tusel et al., 1995).

Although a slight digression from the central theme of this chapter, it is worth noting that the reinforcement of cocaine abstinence in methadone patients has had some broad beneficial effects, beyond its obvious effects on cocaine use (Silverman, Wong, Umbricht-Schneiter et al., 1966). Most notably, contrary to some expectations, in two separate studies (Silverman, Higgins, et al., 1996, Silverman , Wong, Umbricht-Schneiter et al., 1996), reinforcement of cocaine abstinence has produced increases in opiate abstinence, even though patients were not required to provide opiate-free urines to earn vouchers. From a behavioral economic perspective, these data suggest that cocaine and heroin may be complementary reinforcers in some patients.

\section{Manipulating Magnitude Of Abstinence Reinforcement and Opportunity Cost}

While the voucher-based contingency management interventions have been clearly effective in these studies, many patients exposed to these interventions have not achieved sustained abstinence. Data from the study by Silverman, Higgins et al. (1996) illustrates this point. As can be seen in Figure 2, although about half of the patients in this study achieved sustained cocaine abstinence when exposed to the intervention in which they could earn up to $\$ 1155$ in vouchers for providing cocaine-free urines (Abstinence Reinforcement Group), about half of the patients appeared relatively resistant to the intervention and failed to achieve sustained abstinence. (Analyses of urine samples collected during the baseline period before patients were exposed to the 
voucher intervention showed that the treatment resistant patients (i.e., patients who failed to achieve 5 or more weeks of sustained cocaine abstinence) had higher pre-treatment rates of cocaine use than the treatment-responsive patients.)

To address this problem, Silverman, Chutuape, Bigelow and Stitzer (1997) conducted a study to determine if sustained cocaine abstinence could be promoted in treatment-resistant patients by increasing the magnitude of voucher reinforcement. Reinforcement magnitude has been shown in a large body of research to be an important determinant of operant behavior. Twenty nine methadone patients who failed to achieve sustained abstinence when exposed to a 13-week intervention in which they could earn up to $\$ 1155$ in vouchers (exchangeable for goods/services) for providing cocaine-free urines participated in this study. Each patient was exposed, in counterbalanced order, to three 9-week voucher interventions (separated by 4-week baseline periods), in which they could earn up to $\$ 0, \$ 380$, or $\$ 3,400$ in vouchers for providing cocainefree urines. Twenty three patients completed all three voucher conditions. Analyses of urine samples from those 23 patients showed that the longest duration of sustained cocaine abstinence was significantly related to voucher magnitude. Ten of the 23 patients in the high magnitude condition achieved 4 or more weeks of sustained cocaine abstinence, whereas only 2 of 23 patients in the low magnitude condition, and no patients in the zero magnitude condition achieved more than 2 weeks of sustained abstinence. The percent of patients abstinent per week was also significantly related to voucher magnitude. Whereas fewer than 10 and 20 percent of subjects were abstinent at any given time point of the zero and low magnitude conditions, respectively, between 50 and 60 percent of subjects were abstinent during many weeks of the high magnitude condition. These results show that high magnitude voucher-based abstinence reinforcement can promote sustained cocaine abstinence, even in treatment-resistant patients.

\section{CONCLUSIONS}

The analysis proposed in this chapter is essentially an analysis of the interactions of drug use and work as operant behaviors. The conditions under which increases in employment should decrease 
drug use depend on a range of environmental factors. Under typical employment conditions, employment occupies time and thereby restricts the amount of time available for drug use; however, reinforcement contingencies for drug abstinence or penalties for drug use are usually absent or inconsistent. Under these conditions there is little reason to think that employment should markedly reduce drug use. In fact, because money and drugs may serve as complementary reinforcers, employment may increase or sustain drug use by providing money to purchase drugs. Consistent with this notion, two randomized controlled studies evaluating the effects of employing drug abusers in supported jobs (Friedman, 1978; Dickinson et al., 1981) failed to show that employment affected drug use. In these studies, participants were employed in low-paying jobs without explicit contingencies on drug use. Perhaps more to the point, this chapter presented data showing that methadone maintenance patients used heroin and cocaine at fairly high rates even while employed full time (Figure 2).

Research on the contingency management of drug use in treatment populations, and particularly research on voucher-based abstinence reinforcement, shows that providing monetarybased vouchers contingent on drug-free urines can exert a powerful influence on drug use. Voucher-based reinforcement of cocaine can promote long periods of cocaine abstinence in cocaine abusing methadone patients who have proven difficult to treat effectively by other means. This intervention is also effective in promoting abstinence from opiates and from polydrug use. At high voucher magnitudes, the intervention can even produce robust results in some of the most treatment resistant methadone patients. These results suggest that employment could potentially provide therapeutic benefit and reduce drug abuse to the extent that salary for work is made contingent on verified drug abstinence. This contingency might be accomplished, for example, by requiring that an employee provide a drug-free urine each day to gain entrance to the workplace; then pay could be provided contingent on completed workshifts. This chained schedule would essentially make pay contingent both on drug abstinence and work. The studies in treatmentresistant patients suggest that the effectiveness of an employment intervention will not only depend on whether or not salary is made contingent on drug abstinence, but also on the magnitude of the salary. Specifically, high abstinence-contingent salaries will be needed to promote abstinence in 
patients with the most serious drug abuse problems.

The need for high salaries creates a practical dilemma because many chronically unemployed methadone patients lack skills that they would need to earn high salaries (Brewington et al., 1987; Dennis et at., 1993). As an example, Figure 4 shows the academic skill levels of 48 patients of the Center for Addiction and Pregnancy, a drug abuse treatment program in Baltimore for pregnant drug abusers (Silverman, Chutuape, Svikis, Bigelow, \& Stitzer, 1995). The left portion this figure shows subjects' estimated grade levels in reading, spelling, and arithmetic based on the Wide Range Achievement Test. Most subjects were at or below the seventh grade level of academic achievement in reading, spelling and arithmetic, and approximately $25 \%$ of subjects were at or below the fourth grade level in these areas. The right-most column shows the highest grade of education that subjects completed and shows that over half of theses patients did not complete high school. Thus, an effective employment intervention may need to include an intensive skills training program that could equip patients with the skills needed to compete for high paying jobs, thereby establishing a mechanism whereby high salary could be earned and made abstinencecontingent. It is important to note that much of the educational technology needed to teach this population the skills they will need to function effectively in the workplace is currently available (Engelmann \& Carnine, 1982; Johnson and Layng, 1992), although it appears that for a substantial proportion of drug abuse patients, reinforcement contingencies for participation in training will be needed in addition to the existing educational curriculum and teaching practices (Silverman, Chutuape, Bigelow and Stitzer, 1996).

\section{Insert Figure 4 About Here}

We are currently developing an employment-based treatment intervention for chronically unemployed heroin and cocaine abusers based on the principles and research reviewed in this chapter. This therapeutic workplace intervention has three main components: 1) voucher-based reinforcement for abstinence and work; 2) skills training; 3) supported work. Each day prior to entering the 
workplace, participants are required to provide a urine sample. If the sample is drug negative, the participant is allowed to work that day. When the participants then complete the day's work shift, they receive a monetary voucher. Voucher values increase as the number of consecutive days of abstinence and workplace attendance increases. Drug-positive urines or unexcused absences reset the voucher value back to the initial low value. During work hours, participants receive training that they will need to perform a variety of office jobs, including training in basic academic skills, typing, number entry and computer use. Participants who complete this training or who enter the program skilled in these areas are given actual work experience performing data entry and word-processing jobs. Preliminary results from the randomized trial comparing methadone maintenance patients who do (therapeutic workplace group) and do not (control group) receive this intervention suggest that the intervention is attractive to a large proportion of patients and appears to increase abstinence from opiates and cocaine. Controlled research has shown voucher-based abstinence reinforcement to be one of the more effective interventions currently available to treat heroin and cocaine abuse and dependence in hardcore drug abusers (c.f., Silverman, Bigelow, and Stitzer, in press). While this research has demonstrated the potential utility of abstinence reinforcement and opportunity cost in the treatment of drug abuse, the research has not identified a practical means of applying these interventions on a large scale, and herein lies the main point of this chapter: The analysis and research presented suggest that employment could well serve as a vehicle for funding, implementing, and sustaining on a large scale powerful reinforcement contingencies for drug abstinence and substantial opportunity cost for drug use. Research investigating this potential role of employment in drug abuse treatment is only just beginning, but the empirical basis for such a role and the preliminary results of a reinforcement-based employment intervention for drug abusers provide good grounds for continuing this line of development and investigation. 


\section{REFERENCES}

Bass, U. F., \& Woodward, J. A. (1978). Services Research Report. Skills Training and Employment for Ex-Addicts in Washington, D.C.: A report on TREAT. Publication Number (ADM) 78-694. Rockville, MD: National Institute on Drug Abuse.

Bickel, W. K., \& DeGrandpre, R. J. (1995). Price and alternatives: Suggestions for drug policy from psychology. International Journal of Drug Policy, $\underline{6}$, 93-105.

Bickel, W. K., Amass, L., Higgins, S. T., Esch, R. A., Hughes, J. R. (1994) A behavioral treatment for opioid dependence during a burprenorphine detoxification: A preliminary report. In $\mathrm{L}$. S. Harris (Eds.) Problems of Drug Dependence, 1993, NIDA Research Monograph No.141. (pp. 455). NIH Publication No. 94-3749, Government Printing Office, Washington, D.C.

Bickel, W. K., DeGrandpre, R. J., \& Higgins, S. T. (1993). Behavioral economics: a novel experimental approach to the study of drug dependence. Drug and Alcohol Dependence, $\underline{33}, 173-192$.

Bickel, W. K., DeGrandpre, R. J., Higgins, S. T. , Hughes, J. R., and Badger, G. J. (1995). Effects of simulated employment and recreation on drug taking: a behavioral economic analysis. Experimental and Clinical Psychopharmacology, $\underline{3}, 467-476$.

Brewington, V., Arella, L., Deren, S., \& Randell, J. (1987). Obstacles to the utilization of vocational services: An analysis of the literature. International Journal of Addictions, 22, 1091-1118.

Brigham, J., Gross, J., \& Stitzer, M. L. (1994). Effects of restricted work-site smoking policy on employees who smoke. American Journal of Public Health, 84, 773-778.

Carroll, M. E. (1995). Reducing drug abuse by enriching the environment with alternative nondrug reinforcers. In J. Kagel, \& L. Green (Eds.), Advances in Behavioral Economics, Vol 3. (pp. ). Norwood, N.J.: Ablex Publishing Co.

Carroll, M. E., \& Rodefer, J. S. (1993). Income alters choice between drug and an alternative nondrug reinforcer in monkeys. Experimental \& Clinical Psychopharmacology, 1, 110-120.

Carroll, M. E., \& Rodefer, J. S. (1995). Concurrent self-administration of ethanol and an alternative nondrug reinforcer for monkeys: effects of income (session length) on demand for drug. Psychopharmacology, 120, 1-9. 
Condelli, W. S., Fairbank, J. A., Dennis, M. L., \& Rachal, J. V. (1991). Cocaine use by clients in methadone programs: Significance, scope, and behavioral interventions. Joumal of Substance Abuse Treatment, 8, 203-212.

DeGrandpre, R. J., \& Bickel, W. K. (1995). Human drug self-administration in a medium of exchange. Experimental and Clinical Psyhopharmacology, 3, 349-357.

Dennis, M. L., Karuntzos, G. T., McDougal, G. L., French, M. T., \& Hubbard, R. L. (1993). Developing training and employment programs to meet the needs of methadone treatment clients. Evaluation Program Planning, 16, 73-86.

Dickinson, K and Maynard, R. (1981). The Impact of Supported Work on Ex-Addicts: National Supported Work Demonstration, Vol 4 of the Final Report on the Supported Work Evaluation. New York: Manpower Demonstration Research Corporation.

Dunteman, G. H., Condelli, W. S., \& Fairbank, J. A. (1992). Predicting cocaine use among methadone patients: Analysis of findings from a national study. Hospital \& Community Psychiatry, 43, 608-611.

Elsmore, T. F., Fletcher, G. V., Conrad, D. G., \& Sodetz, F. J. (1980). Reduction of heroin intake in baboons by an economic constraint. Pharmacology, Biochemistry and Behavior, 13,729 731.

Engelmann, S. and Carnine, D. (1982). Theory of Instruction: Principles and Applications. New York: Irvington Publishers, Inc.

Friedman, L. (1980). Employing the ex-addict: an experiment in supported work. In I. Leveson (Ed.) Quantitative Explorations in Drug Abuse Policy. Jamaica, NY: Spectrum Publications, Inc.

Frykholm, B. Gunne, M., \& Huitsfeldt, B. (1976). Prediction of outcome in drug dependence. Addictive Behaviors, 1 , 103-110.

GAO (1990). GAO Report to the Chairman, Select Committee on Narcotics Abuse and Control, House of Representatives: Methadone Maintenance: Some Treatment Programs are Not Effective: Greater Oversight Needed, March 1990. GAO/HRD-90-194, Washington, DC: United 
States General Accounting Office.

Gfroerer, J. C., \& Brodsky, M.D. (1993). Frequent cocaine users and their use of treatment. American Journal of Public Health, $\underline{83}, 1149-1154$.

Green, L., \& Freed, D. E. (1993). The substitutability of reinforcers. Journal of the Experimental Analysis of Behavior, 60 , 141-158.

Griffiths R. R, Bigelow G. E., \& Henningfield J. E. (1980). Similarities in animal and human drug-taking behavior. In N. K. Mello (Ed.) Advances in Substance Abuse. (pp. 1-90). Greenwich, JAI Press.

Hall, S. M. (1990). Clinical trials in drug treatment: Methodology. In S. W. Gust, J. M. Walsh, L. B. Thomas, D. J. Crouch (Eds.) Drugs in the Workplace: Research and Evaluation Data. Volume II. Research Monograph. 100. (pp. 88-105). DHHS Publication Number (ADM) 91-1730. Rockville, MD: National Institute on Drug Abuse.

Hall, S. M., Bass, A., Hargreaves, W. A., \& Loeb, P. (1979). Contingency management and information feedback in outpatient heroin detoxification. Behavior Therapy $10,443-451$.

Higgins, S. T. (1996). Some potential contributions of reinforcement and consumerdemand theory to reducing cocaine use. Addictive Behaviors, 21 , 803-816.

Higgins, S. T., Budney, A. J., Bickel, W. K., Foerg, F., Donham, R., \& Badger, M. S. (1994). Incentives improve outcome in outpatient behavioral treatment of cocaine dependence. Archives of General Psychiatry, 51, 568-576.

Higgins, S. T., Delaney, D. D., Budney, A. J., Bickel, W. K., Hughes, J. R., Foerg, F., \& Fenwick, J. W. (1991). A behavioral approach to achieving initial cocaine abstinence. American Journal of Psychiatry, 148, 1218-1224.

Higgins, S. T., Stitzer, M. L., Bigelow, G. E., \& Liebson, I. A. (1986). Contingent methadone delivery: effects on illicit opiate use. Drug and Alcohol Dependence, 17, 311-322.

Hubbard, R. L., Marsden, M. E., Rachal, J. V., Harwood, H. J., Cavanaugh, E. R., \& Ginzburg, H. M. (1989). Drug Abuse Treatment: A National Study of Effectiveness. Chapel Hill: The University of North Carolina Press. 
Hursh, S. R. (1978). The economics of daily consumption controlling food- and waterreinforced responding. Journal of the Experimental Analysis of Behavior, 29, 475-491.

Hursh, S. R. (1993). Behavioral economics of drug self-administration: an introduction. Drug and Alcohol Dependence, 33, 165-172.

Johanson, C. E., \& Schuster C. R. (1981). Animal models of drug self-administration. In N. K. Mello (Ed.) Advances in Substance Abuse: Behavioral and Biological Research (pp. 219-297). JAI Press, Greenwich.

Johnson, K. R., \& Layng, T. V. J. (1992). Breaking the structuralist barrier: Literacy and Numeracy with fluency. American Psychologist, 47, 1475-1490.

Kidorf, M., \& Stitzer, M. L. (1993). Contingent access to methadone maintenance treatment: effects on cocaine use of mixed opiate-cocaine abusers. Experimental and Clinical Pharmacology, 1, 200-206.

Kidorf, M., \& Stitzer, M. L. (1996). Contingent use of take-homes and split-dosing to reduce illicit drug use of methadone patients. Behavior Therapy. 27, 41-51.

Kirby, K. C., Lamb, R. J., Iguchi, M. Y., Husband, S. D., \& Platt, J. J. (1995). Situations occasioning cocaine use and cocaine abstinence strategies. Addiction, $\underline{90}, 1241-1252$.

McCarthy, J. J., \& Borders, O. T. (1985). Limit setting on drug abuse in methadone maintenance patients. American Journal of Psychiatry, 142, 1419-1423.

McCaul, M. E., Stitzer, M. L., Bigelow, G. E., \& Liebson, I. A. (1984). Contingency management interventions: effects on treatment outcome during methadone detoxification. Journal of Applied Behavior Analysis, 17, 35-43.

McLellan, A. T., Arndt, I. O., Metzger, D. S., Woody, G. E., \& O'Brien, C. P. (1993). The Effects of psychosocial services in substance abuse treatment. Journal of the American Medical Association, 269, 1953-1996.

McLellan, A. T., Luborsky, L., Woody, G. E., O'Brien, C. P., \& Druley, K. A. (1983). Predicting response to alcohol and drug abuse treatment. Archives of General Psychiatry, 4. 620-625. McLellan, A., Ball, J. Rosen, L., \& O'Brien, C. (1981) Pretreatment source of income and 
response to methadone maintenance: A follow-up study. American Journal of Psychiatry, 138, 785 789.

Milby, J. B., Garrett, C., English, C., Fritschi, O., \& Clarke, C. (1978). Take-home methadone: contingency effects on drug seeking and productivity of narcotic addicts. Addictive Behaviors, 3, 215-220.

NIDA. (1988). National Household Survey on Drug Abuse: Main Findings 1985. DHHS Publication No. (ADM) 88-1586, U.S. Government Printing Office, Washington, D.C.

NIDA. (1990). National Household Survey on Drug Abuse: Main Findings 1988. DHHS Publication No. (ADM) 90-1682, U.S. Government Printing Office, Washington, D.C.

NIDA. (1991). National Household Survey on Drug Abuse: Main Findings. DHHS Publication No. (ADM) 91-1788, U.S. Government Printing Office, Washington, D.C.

Osborn, C. E., \& Sokolov, J. J. (1989). Drug use trends in a nuclear power company: Cumulative data from an ongoing testing program. National Institute on Drug Abuse: Research Monograph Series. No 91. (pp. 69-80), Rockville, MD. National Institute on Drug Abuse.

Pickens, R. Meisch, R. A., \& Thompson T. (1978). Drug self-administration: an analysis of the reinforcing effects of drugs. In L. L. Iversen, S. D. Iversen, \& S. H. Snyder (Eds.) Handbook of Psychopharmacology (pp. 1-37). New York: Plenum.

Platt, J. J. (1995) Vocational rehabilitation of drug abusers. Psychological Bulletin, 117, 416-433.

Rawson, R. A., McCann, M. J., Hasson, A. J., \& Ling, W. (1994). Cocaine abuse among methadone maintenance patients: Are there effective treatment strategies? Journal of Psychoactive Drugs, 26, 129-136.

SAMHSA. (1993). National Household Survey on Drug Use: Main Findings 1991. Department of Health and Human Services, Public Health Service, Substance Abuse and Mental Health Services Administration, DHHS Publication No (SMA) 93-1980, Rockville, MD.

SAMHSA. (1996). Drug use among U.S. workers: Prevalence and trends by occupation and industry categories. Department of Health and Human Services, Public Health Service, Substance 
Abuse and Mental Health Services Administration. DHHS Publication No. (SMA) 96-3089, Rockville, MD.

Shaner, A. E,. Eckman, T. T., Roberts, L. J., Wilkens, J. N., Tucker, D. E., Tsuang, J. W., \& Mintz, J. (1995). Disability income, cocaine use, and repeated hospitalization among schizophrenic cocaine abusers. New England Journal of Medicine, $\underline{333}, 777-783$.

Silverman, K., Bigelow, G. E., \& Stitzer, M. L. (in press). Treatment of cocaine abuse in methadone patients. In S. T. Higgins, \& J. L. Katz (Eds.), Cocaine Abuse Research: Pharmacology, Behavior, and Clinical Applications. San Diego, CA: Academic Press, Inc.

Silverman, K., Chutuape, M.A., Svikis, D. S., Bigelow, G. E., \& Stitzer, M. L. (1995). Incongruity between occupational interests and academic skills in drug abusing women. Drug and Alcohol Dependence, 40, 115-123.

Silverman, K., Chutuape, M.A., Bigelow, G. E., \& Stitzer, M. L. (1996). Voucherbased reinforcement of attendance by unemployed methadone patients in a job skills training program, Drug and Alcohol Dependence, 41, 197-207.

Silverman, K., Chutuape, M. A. D., Bigelow, G. E., and Stitzer, M. L. (1997). Reinforcement of cocaine abstinence in treatment-resistant patients: Effects of reinforcer magnitude. In L. S. Harris (Ed.) Problems of Drug Dependence, 1996, (pp. 74). NIDA Research Monograph No. 174, NIH Publication No. 97-4236, Washington, DC: U.S. Government Printing Office.

Silverman, K., Higgins, S. T., Brooner, R. K., Montoya, I. D., Cone, E. J., Schuster, C. R., \& Preston. K. L. (1996). Sustained cocaine abstinence in methadone patients through voucher-based reinforcement therapy. Archives of General Psychiatry, 53, 409-415.

Silverman, K., Kirby, K. C., \& Griffiths, R. R. (1994). Modulation of drug reinforcement by the behavioral requirements following drug ingestion. Psychopharmacology, 114, 243-247.

Silverman, K., Mumford, G. K., \& Griffiths, R. R. (1994). Enhancing caffeine reinforcement by behavioral requirements following drug ingestion. Psychopharmacology, 114, 424- 
432.

Silverman, K., Wong, C. J., Umbricht-Schneiter, A., Montoya, I. D., Schuster, C. R., \& Preston, K. L. (1996). Voucher-based reinforcement of cocaine abstinence: Effects of reinforcement schedule. In L. S. Harris (Ed.) Problems of Drug Dependence 1995, (pp. 97). NIDA Research Monograph No. 162, NIH Publication No. 96-4116, Washington, DC: Government Printing Office.

Silverman, K., Wong, C. J., Higgins, S. T., Brooner, R. K., Montoya, I. D., Contoreggi, C., Umbritch-Schneiter, A., Schuster, C. R., \& Preston, K. L. (1996). Increasing opiate abstinence through voucher-based reinforcement therapy. Drug and Alcohol Dependence, 41, $157-165$.

Stephens, R., \& Cottrell, E. (1982). A follow-up study of 200 narcotic addicts committed for treatment under the Narcotics Rehabilitation Act (NRA). British Journal of Addiction, 67, 45-53.

Stitzer, M. L. (1995). Policy initiatives to enhance smoking cessation and harm reduction. Tobacco Control, 4 (suppl 2), S67-S74.

Stitzer, M. L., \& Higgins, S. T. (1995). Behavioral treatment of drug and alcohol abuse. In F. E. Bloom, \& D. J. Kupfer (Eds.) Psychopharmacology: The Fourth generation of Progress. (pp. 1807-1819). Raven Press, Ltd., New York.

Stitzer, M. L., Bigelow, G. E., Liebson, I. A., \& Hawthorne, J. W. (1982). Contingent reinforcement for benzodiazepine-free urines: evaluation of a drug abuse treatment intervention. Journal of Applied Behavior Analysis, 15, 493-503.

Stitzer, M. L., Iguchi, M. Y., \& Felch, L. J. (1992). Contingent take-home incentive: effects on drug use of methadone maintenance patients. Journal of Consulting and Clinical Psychology, 60, 927-934.

SAMHSA (1993). National Household Survey on Drug Use: Main Findings 1991. U.S. Department of Health and Human Services, Public Health Service, DHHS Publication No (SMA) 93 1980. Rockville, MD: Substance Abuse and Mental Health Services Administration.

SAMHSA (1996). Drug Use Among U.S. Workers: Prevalence and Trends by Occupation 
and Industry Categories. U.S. Department of Health and Human Services, Public Health Service, DHHS Publication No (SMA) 96-3089. Rockville, MD: Substance Abuse and Mental Health Services Administration.

Tusel, D. J., Piotrowski, N. A., Sees, K., Reilly, P. M., Banys, P., Meek, P., \& Hall, S. M. (1995). Contingency contracting for illicit drug use with opioid addicts in methadone treatment. In L. S. Harris (Ed.) Problems of Drug Dependence, 1994, (pp. 155). NIDA Research Monograph No. 153, Washington, DC: Government Printing Office.

Vaillant, G. E. (1966a). A 12 year follow-up of New York narcotic addicts: I. The relation of treatment of outcome. American Journal of Psychiatry, 122, 727-737.

Vaillant, G. E. (1966b). A 12 year follow-up of New York narcotic addicts: II. The natural history of a chronic disease. New England Journal of Medicine, 275, 1282-1288.

Vaillant, G. E. (1988). What can long-term follow-up teach us about relapse and prevention of relapse in addiction? British Journal of Addiction. 83, 1147-1157. 


\section{FIGURE LEGENDS}

Figure 1. Percent of adults (18-49 years old) reporting illicit drug use by employment status from 1985 to 1993. Data are derived from the National Household Survey on Drug Abuse, which is a survey conducted periodically by the U.S. federal government of residents of households, noninstitutionalized group residences (e.g., shelters), and civilians living on military bases. Points represent the percent of respondents reporting that they used illicit drug use in the past month. Adapted from Table 2.1 in SAMHSA, 1996.

Figure 2. Drug use of employed $(\mathrm{N}=50$; shaded bars) and unemployed ( $N=101$; open bars) methadone patients during the first 5 weeks of methadone maintenance treatment $(60 \mathrm{mg}$ methadone per day). Left panel shows the number of injections per week reported by patients over the 5 weeks of period. Self-reports were collected once per week with computerized questionnaires. Right panel shows the percent of urines positive for opiates or cocaine over the same time period. Urines were collected 3 times per week. Bar represent mean values; brackets represent + 1 S.E.M. Within each panel, an asterisk indicates that the means for the employed and unemployed were significantly different (t-test; $\mathrm{P} \leq .05)$.

Figure 3. Longest duration of sustained cocaine abstinence achieved during the 12-week voucher condition. Each point represents data for an individual patient and the lines represent group means. The 19 abstinence reinforcement patients are displayed in the left column (circles) and the 18 control patients in the right (squares). Open symbols represent patients who dropped out of the study early. From Silverman et al., Archives of General Psychiatry, 53, 409-415, 1996.

Figure 4. WRAT3 reading, spelling, and arithmetic grade levels and the highest grade level actually completed during school years for 48 subjects (patients of the Center for Addiction and Pregnancy). Solid points indicate grade levels for individual subjects; horizontal lines represent group means.

From Silverman et al., 1995, Drug and Alcohol Dependence, 40, 115-123. 
Percent of Adults Reporting Illicit Drug Use

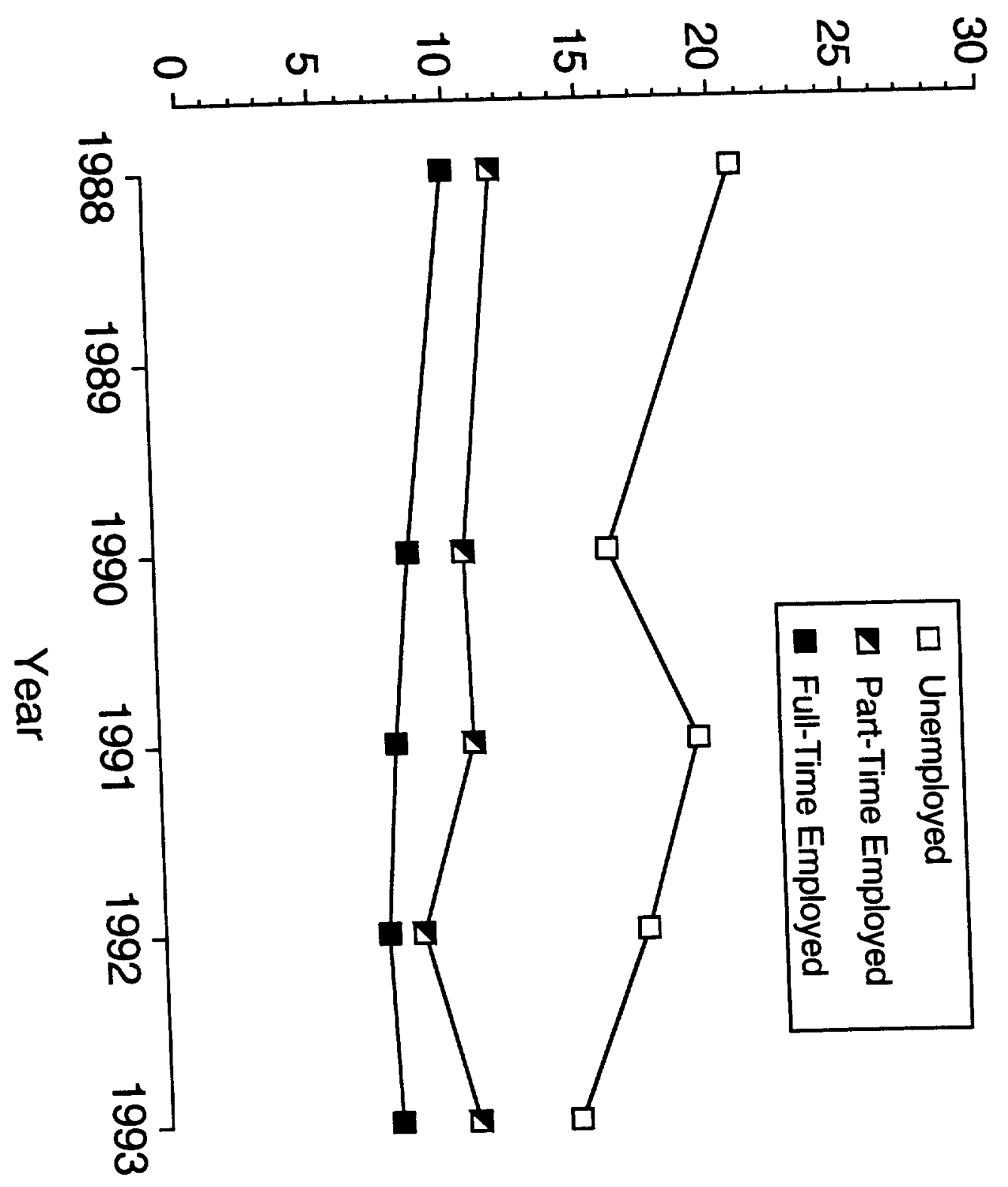


Number

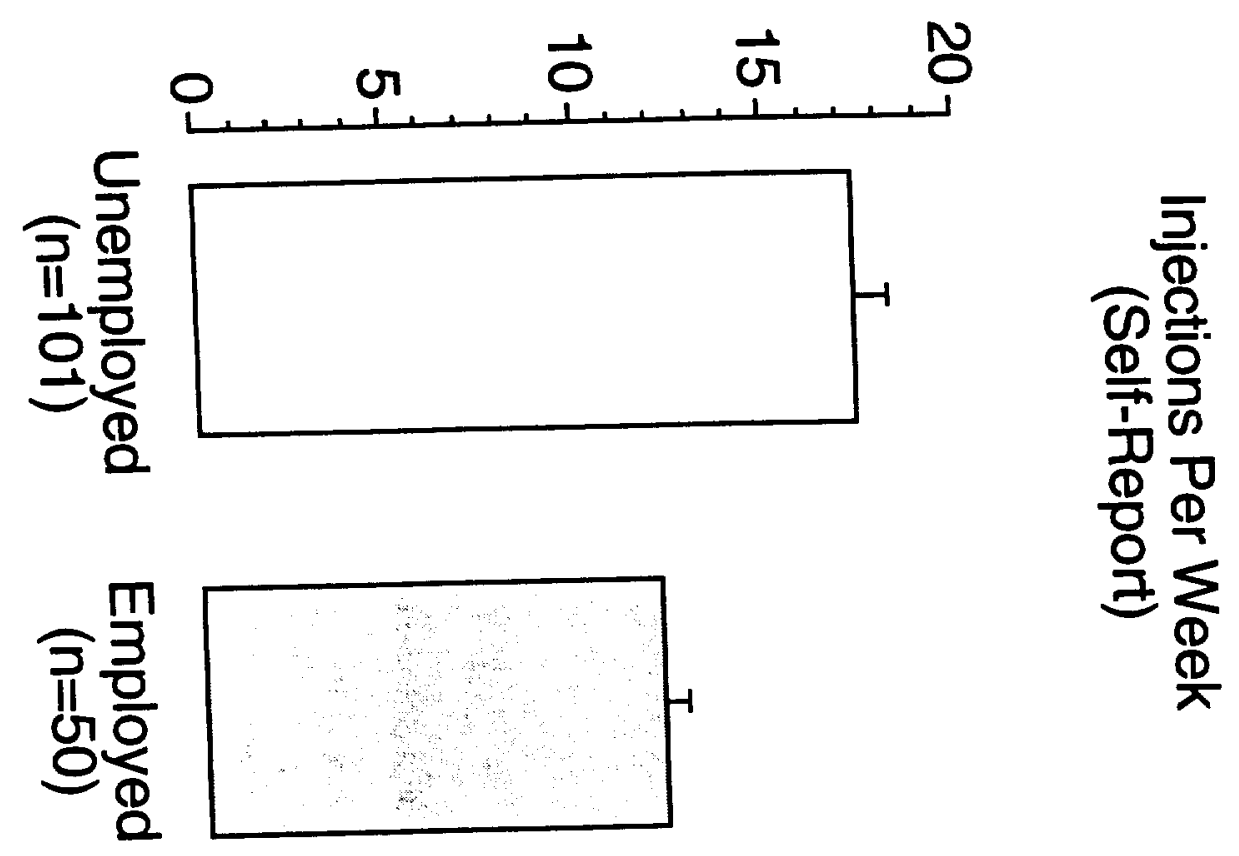

Percent

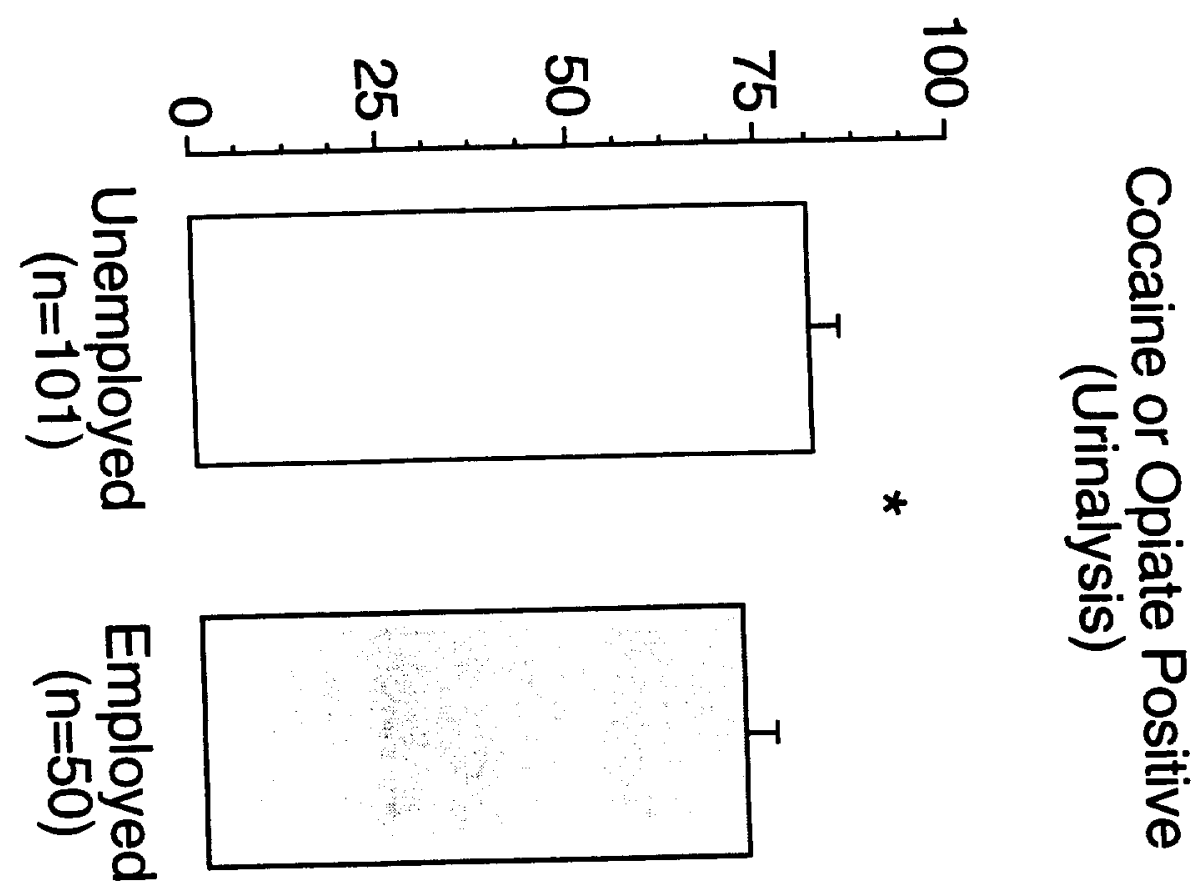




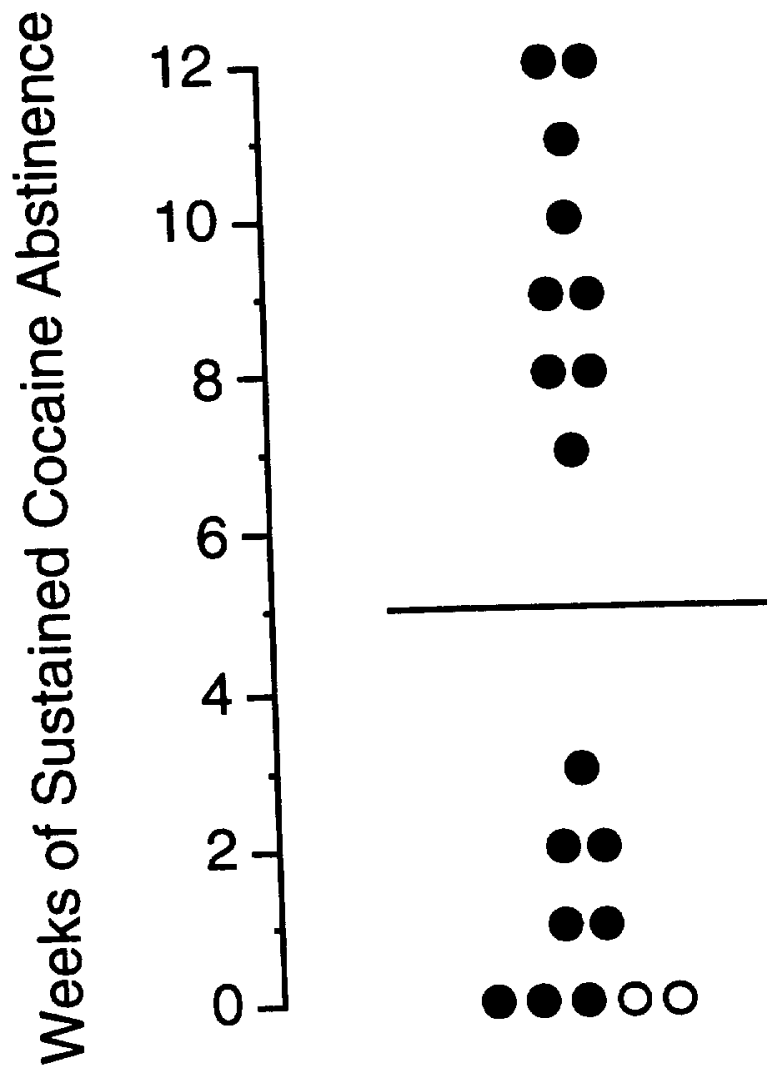

Abstinence Reinforcement

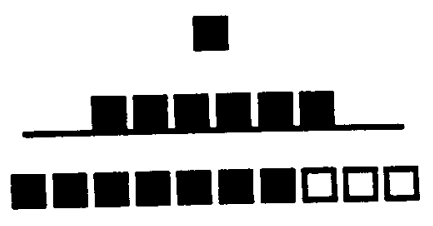

Control 

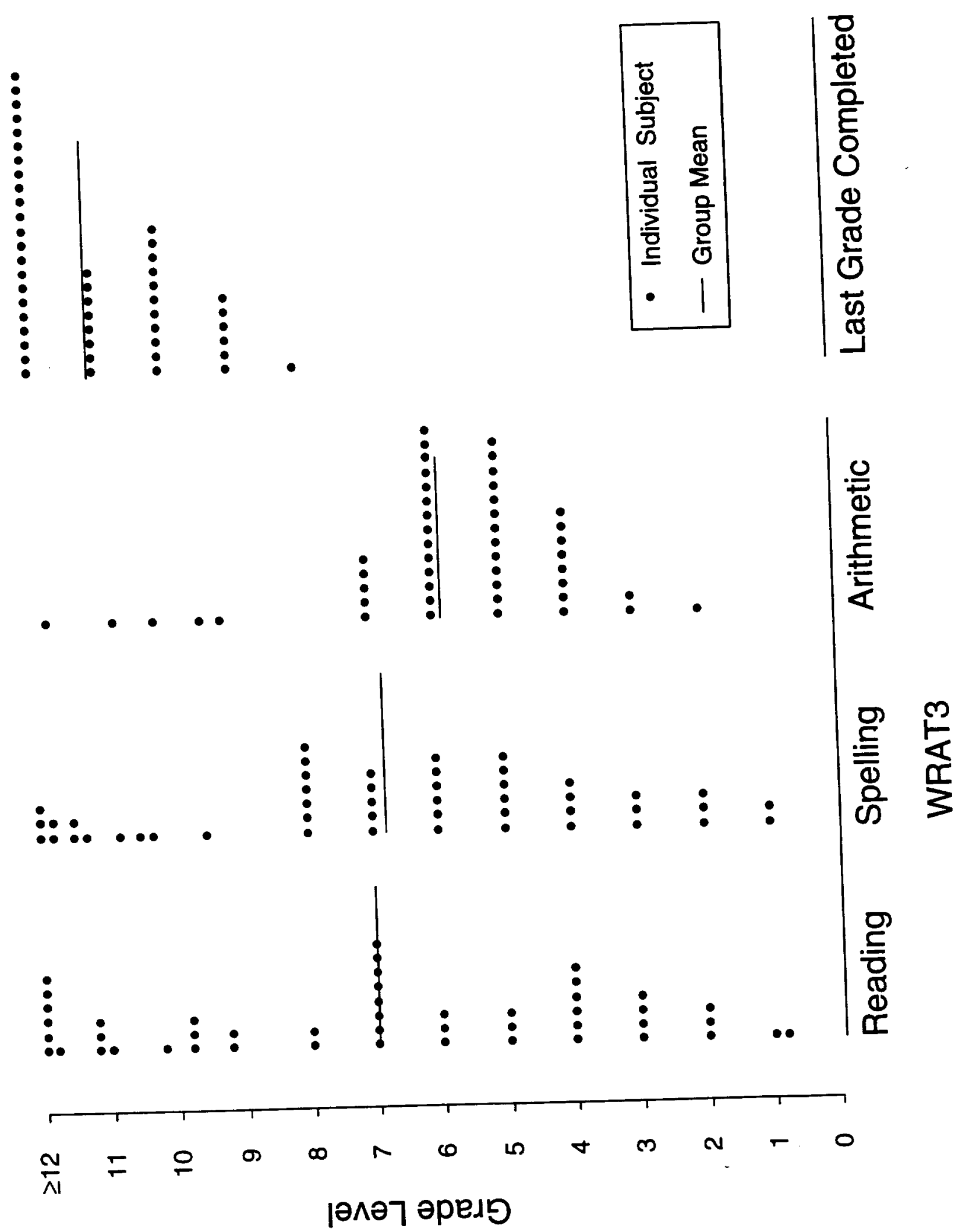